\title{
Prediction of multiband luminescence due to the gallium vacancy-oxygen defect complex in GaN
}

Zijuan Xie, Yu Sui, John Buckeridge, Alexey A. Sokol, Thomas W. Keal, and Aron Walsh

Citation: Appl. Phys. Lett. 112, 262104 (2018); doi: 10.1063/1.5026751

View online: https://doi.org/10.1063/1.5026751

View Table of Contents: http://aip.scitation.org/toc/apl/112/26

Published by the American Institute of Physics

\section{Articles you may be interested in}

Alloy disorder limited mobility of InGaN two-dimensional electron gas

Applied Physics Letters 112, 262101 (2018); 10.1063/1.5030992

Experimental characterization of impact ionization coefficients for electrons and holes in GaN grown on bulk GaN substrates

Applied Physics Letters 112, 262103 (2018); 10.1063/1.5031785

Band alignment of $\mathrm{AIN} / \mathrm{\beta}-\mathrm{Ga}_{2} \mathrm{O}_{3}$ heterojunction interface measured by $\mathrm{x}$-ray photoelectron spectroscopy

Applied Physics Letters 112, 261602 (2018); 10.1063/1.5035372

Structural and electronic properties of a-edge dislocations along $\langle 1-100\rangle$ in $\mathrm{GaN}$

Journal of Applied Physics 123, 244301 (2018); 10.1063/1.5034198

Leakage mechanisms in GaN-on-GaN vertical pn diodes

Applied Physics Letters 112, 233501 (2018); 10.1063/1.5033436

On compensation in Si-doped AIN

Applied Physics Letters 112, 152101 (2018); 10.1063/1.5022794

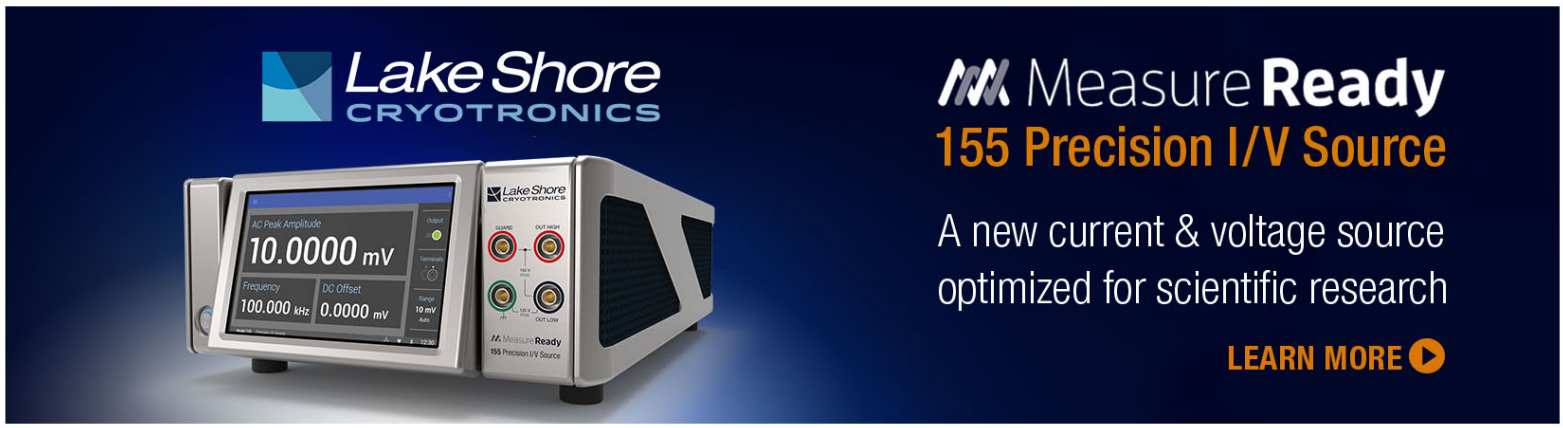




\title{
Prediction of multiband luminescence due to the gallium vacancy-oxygen defect complex in GaN
}

\author{
Zijuan Xie, ${ }^{1,2}$ Yu Sui, ${ }^{1}$ John Buckeridge, ${ }^{3}$ Alexey A. Sokol, ${ }^{3}$ Thomas W. Keal, ${ }^{4}$ \\ and Aron Walsh ${ }^{2,5}$ \\ ${ }^{1}$ Department of Physics, Harbin Institute of Technology, Harbin 15000, China \\ ${ }^{2}$ Department of Materials, Imperial College London, London SW7 2AZ, United Kingdom \\ ${ }^{3}$ Kathleen Lonsdale Materials Chemistry, Department of Chemistry, University College London, \\ London WC1H OAJ, United Kingdom \\ ${ }^{4}$ Scientific Computing Department, Daresbury Laboratory, STFC, Daresbury, Warrington WA4 4AD, \\ United Kingdom \\ ${ }^{5}$ Department of Materials Science and Engineering, Yonsei University, Seoul 03722, South Korea
}

(Received 23 February 2018; accepted 8 June 2018; published online 27 June 2018)

\begin{abstract}
Oxygen is the most common unintentional impurity found in GaN. We study the interaction between substitutional oxygen $\left(\mathrm{O}_{\mathrm{N}}\right)$ and the gallium vacancy $\left(\mathrm{V}_{\mathrm{Ga}}\right)$ to form a point defect complex in GaN. The formation energy of the gallium vacancy is largely reduced in n-type GaN by complexing with oxygen, while thermodynamic and optical transition levels remain within the bandgap. We study the spectroscopy of this complex using a hybrid quantum-mechanical molecular-mechanical embedded-cluster approach. We reveal how a single defect center can be responsible for multiband luminescence, including possible contributions to the ubiquitous yellow luminescence signatures observed in n-type GaN, owing to the coexistence of diffuse (extended) and compact (localized) holes. Published by AIP Publishing. https://doi.org/10.1063/1.5026751
\end{abstract}

Gallium nitride $(\mathrm{GaN})$ is an important semiconductor for optoelectronic and high-power devices such as lightemitting diodes and laser diodes. ${ }^{1}$ In these devices, n-type doping of $\mathrm{GaN}$ is often achieved by incorporating oxygen $(\mathrm{O})$ impurities that substitute a nitrogen $(\mathrm{N})$ ion and donate free electrons to the conduction band. ${ }^{2}$ Oxygen also tends to be present in undoped $\mathrm{GaN}$, which is natively of n-type. ${ }^{3} \mathrm{In}$ most n-type GaN samples, a yellow luminescence (YL) feature that has a peak at about $2.1-2.3 \mathrm{eV}$ has been widely observed regardless of the growth technique used, which varies from molecular beam epitaxy (MBE) ${ }^{4}$ and metalorganic chemical vapor deposition (MOCVD) $)^{5-7}$ to hydride vapor phase epitaxy (HVPE). ${ }^{7-9}$ In some samples, the YL band is accompanied by red luminescence (RL) ${ }^{7,10}$ or green luminescence (GL). ${ }^{8,11}$

The source (or sources) of YL is the subject of an ongoing debate in the literature. Ogino and Aoki first proposed that $\mathrm{YL}$ is due to a radiative transition from a shallow donor with a depth of $25 \mathrm{meV}$ to a deep acceptor with a depth of $860 \mathrm{meV} .{ }^{12}$ From first-principles density-functional theory (DFT) calculations, Neugebauer and Van de Walle attributed this deep acceptor to a gallium vacancy $\left(\mathrm{V}_{\mathrm{Ga}}\right.$, or related complex), which has a transition level $1.1 \mathrm{eV}$ above the valence band maximum (VBM), while carbon (C) substituting for $\mathrm{N}$ $\left(\mathrm{C}_{\mathrm{N}}\right)$ is a shallow acceptor. ${ }^{13}$ Later, calculations using hybrid DFT predicted $\mathrm{C}_{\mathrm{N}}$ to be a deep acceptor which has an ionization energy of $0.90 \mathrm{eV}$ and is another plausible source of YL. ${ }^{14}$ Furthermore, by combining hybrid DFT and experimental measurements, Demchenko et al. found that the $\mathrm{C}_{\mathrm{N}^{-}}$ $\mathrm{O}_{\mathrm{N}}$ complex is energetically favorable and its $(0 /+)$ thermodynamic transition deep-donor level is at $0.75 \mathrm{eV}$ above the VBM, which gives rise to the YL. ${ }^{15}$ They also ruled out $C_{N}$ and $\mathrm{V}_{\mathrm{Ga}}-\mathrm{O}_{\mathrm{N}}$ as the sources of YL. Lyons et al., ${ }^{16}$ again using hybrid DFT, predicted a $2.27 \mathrm{eV}$ emission peak for radiative hole capture by $\mathrm{V}_{\mathrm{Ga}}{ }^{3-}$, which, however, has a high formation energy. Instead, they found that donor impurities significantly lower $\mathrm{V}_{\mathrm{Ga}}$ transition levels and that $\mathrm{V}_{\mathrm{Ga}}-3 \mathrm{H}$ and $\mathrm{V}_{\mathrm{Ga}^{-}}{ }^{-}$ $\mathrm{O}_{\mathrm{N}}-2 \mathrm{H}$ complexes may give rise to $\mathrm{YL}$. Experimentally, $\mathrm{YL}$ has been attributed to $\mathrm{V}_{\mathrm{Ga}}$ (and/or related complexes) ${ }^{5,8,9}$ or C-related defects, ${ }^{11,17}$ or both, ${ }^{6}$ or neither. ${ }^{7}$ There is experimental evidence that localization of holes is involved in YL. ${ }^{6,9,18} \mathrm{Xu}$ et al. found that a GaN film with a shorter positron diffusion length exhibits stronger YL and suggested that the spatial localization of holes is a vital factor to enhance the YL efficiency. ${ }^{6}$ Reshchikov attributed YL and GL bands in high-purity undoped $\mathrm{GaN}$ to an acceptor binding one and two holes, respectively. ${ }^{9} \mathrm{~V}_{\mathrm{Ga}}$ complexes have also been studied as non-radiative recombination centers by calculations ${ }^{19}$ and experiments. ${ }^{20,21}$

The sources of the RL and GL bands that are often observed together with YL are also unclear. Some photoluminescence (PL) spectra show multiple YL and GL bands. ${ }^{22}$ They are often suggested to be caused by the same defect. ${ }^{23}$ From time-resolved photoluminescence (PL) spectra, Reshchikov et al. observed that a GL band disappears at longtime decays and YL and RL bands become dominant, while in the steady-state PL, the GL band is not observed in the timeresolved PL spectra, but the YL and RL bands can be resolved. ${ }^{24}$ Bozdog et al. observed overlapping RL, YL, and GL bands in GaN grown by HVPE. They followed a two-stage model, in which the luminescence arises from hole capture at the defect after an electron capture process. ${ }^{18}$ Díaz-Guerra et al. found two YL bands peaked at 2.22 and $2.03 \mathrm{eV}$ and a $\mathrm{RL}$ band at about $1.85 \mathrm{eV}$ which dominates spectra recorded for long delay times. ${ }^{10}$ Reshchikov et al. first observed the fine structure of the RL band with a maximum at $1.8 \mathrm{eV}$ and a zero-phonon line (ZPL) at $2.36 \mathrm{eV}^{.25}$ they then attributed this to a YL band often covered by the RL band. ${ }^{24}$ 
$\mathrm{V}_{\mathrm{Ga}}$ as a native defect has been widely discussed, based on DFT calculations, as the reason for YL, as it is an acceptor and thus has lower formation energy in $n-G a N{ }^{13}$ The calculated formation energies of neutral $\mathrm{V}_{\mathrm{Ga}}$ under $\mathrm{N}$-rich conditions using different functionals are close, about $6.5 \mathrm{eV}^{26-31}$ However, the transition levels of $\mathrm{V}_{\mathrm{Ga}}$ across the bandgap differ, which render different formation energies of $\mathrm{V}_{\mathrm{Ga}}$ near the conduction band minimum (CBM), when in a -3 charge state. Transition levels of $\mathrm{V}_{\mathrm{Ga}}$ are closer to the conduction band when comparing the results from local (or semilocal) DFT to hybrid functionals that are capable of describing hole localization. ${ }^{16}$ The associated formation energy of $\mathrm{V}_{\mathrm{Ga}}$ at the $\mathrm{CBM}$ varies with exchange-correlation functional from about $0 \mathrm{eV}$ (local) ${ }^{26}$ to $4.4 \mathrm{eV}$ (hybrid). ${ }^{16}$ The higher formation energy from hybrid-DFT calculations indicates that $\mathrm{V}_{\mathrm{Ga}}$ may not be thermodynamically abundant even under n-type GaN. However, the formation of $\mathrm{V}_{\mathrm{Ga}}$ is more likely if it forms a complex with impurities like $\mathrm{O}$ or $\mathrm{H}$, as has been shown in calculations. ${ }^{13,16,32}$ Indeed, positron annihilation spectroscopy has been used to verify the decoration of Ga vacancies in GaN by $\mathrm{O}$ or $\mathrm{H}$, while the observed concentrations of decorated vacancies in those experiments have been confirmed using thermal transport measurements. ${ }^{33-35}$

Thus, until now, the origin of YL is not clear, and the specific transitions and point defects or complexes that contribute to observed YL features remain a matter of debate. $\mathrm{O}_{\mathrm{N}}$ is common in $\mathrm{n}-\mathrm{GaN}$ as a dopant or impurity, and the $\mathrm{YL}$ in $\mathrm{n}-\mathrm{GaN}$ has been suspected to be related to $\mathrm{V}_{\mathrm{Ga}}$, which is likely to form a complex with a donor impurity such as $\mathrm{O}$. In this letter, we report a quantum mechanical/molecular mechanical (QM/ MM) embedded cluster study of $\mathrm{V}_{\mathrm{Ga}} \mathrm{O}_{\mathrm{N}}$ to illuminate its optical and electronic properties, especially its effect on luminescence and potential contribution to YL, GL, and RL.

The QM/MM embedded cluster technique employed describes accurately localized states in ionic solids, where charged and strongly dipolar species predominantly interact via long-range electrostatic and short-range exchange forces. $^{36,37}$ This method and a plethora of closely related embedding approaches ${ }^{38}$ split extended systems into an inner region containing the central defect, described using molecular QM theories, and its surroundings, which are only slightly perturbed by the defect, modelled with MM approaches.

Our choice of QM methodology is DFT; the MM simulations employ polarizable shell model interatomic potentials, and the interface between these two regions is based on cationcentred semi-local pseudopotentials. The inner cluster of 116 atoms of $\mathrm{GaN}$ centred on the defect is treated using (i) the second-generation thermochemical hybrid exchange and correlation (XC) density functional B97-2, ${ }^{39}$ which is similar to those commonly used in recent plane-wave supercell calculations $\left(21 \%\right.$ exact exchange compared with $25 \%$ for $\mathrm{PBE}^{40}$ or HSE $06^{41}$ ), (ii) small-core pseudopotentials on $\mathrm{Ga}^{42}$ within the cluster and large-core refitted pseudopotentials ${ }^{43,44}$ in the interface which provide a short-range contribution to the embedding potential on the defect, and (iii) the atomic basis set of def2-TZVP quality on $\mathrm{N}^{45}$ and matching SBKJC basis on $\mathrm{Ga}^{42}$ For comparison, we use a second hybrid XC density functional employing $42 \%$ exact exchange (BB1k), ${ }^{46}$ fitted to reproduce kinetic barriers and thermochemical data, which gives a more accurate description of electron localization than
B97-2. ${ }^{44,47}$ The QM region of radius $6.8 \AA$ is embedded in an outer cluster of radius $30 \AA$, which is treated with an MM level of theory using two-body interatomic potentials parameterized to reproduce the $\mathrm{GaN}$ bulk structure and physical properties. ${ }^{44,48}$ The method has been implemented in the ChemShell package ${ }^{36,37,49}$ that employs Gamess$\mathrm{UK}^{50}$ for the QM and GULP ${ }^{51}$ for MM single point energy and gradient calculations. Further technical details are discussed elsewhere. ${ }^{36,52}$ This method has been applied to treat defects in $\mathrm{AgCl}^{53} \mathrm{ZnO}^{54}$ and $\mathrm{GaN}^{44}$ and the band alignment of polymorphs of $\mathrm{TiO}_{2}{ }^{44,55}$

The formation energy of a point defect $X\left(E_{D}[X]\right)$ is determined from the grand-canonical expression

$$
E_{D}[X]=\Delta E(X)-\sum_{i} n_{i} \mu_{i}+q E_{F},
$$

where $\Delta E(X)$ is the difference in energy between the embedded cluster with and without $X, n_{i}$ is the number of atoms of species $i$ added $\left(n_{i}>0\right)$ or subtracted $\left(n_{i}<0\right)$ in forming $X$, $\mu_{i}$ is the chemical potential of species $i, q$ is the charge of $X$, and $E_{F}$ is the Fermi energy. $\mu_{i}$ depends on the experimental growth condition, which can be either $\mathrm{N}$ or $\mathrm{Ga}$ rich. The binding energy of the $\mathrm{V}_{\mathrm{Ga}}-\mathrm{O}_{\mathrm{N}}$ complex is determined from the general process ${ }^{56}$

$$
E_{D}\left[V_{G a}^{m}\right]+E_{D}\left[O_{N}^{n}\right] \rightarrow E_{D}\left[\left(V_{G a}-O_{N}\right)^{p}\right]+(m+n-p) E_{F}+E_{B},
$$

where $m, n$, and $p$ are the charge states and $E_{B}$ is the binding energy of the complex; a positive value means that the complex is likely to form.

$\mathrm{GaN}$ adopts a wurtzite structure $\left(\mathrm{C}_{6 \mathrm{v}}\right.$ point group), where each $\mathrm{Ga}(\mathrm{N})$ is surrounded by four $\mathrm{N}(\mathrm{Ga})$, one in the axial $c$ direction and the other three equivalently in a basal plane. We thus consider two geometries of the $\mathrm{V}_{\mathrm{Ga}^{-}} \mathrm{O}_{\mathrm{N}}$ complex: $\mathrm{V}_{\mathrm{Ga}}$ with an $\mathrm{O}$ substituting an axial $\mathrm{N}$ or a basal $\mathrm{N}$. The formation energies of these two geometries are almost identical, as shown in Fig. 1. The formation energy difference between Garich and $\mathrm{N}$-rich conditions comes from the chemical potential of $\mathrm{O}$, taken from the heats of formation (and relevant atomic ionization energies) of $\mathrm{Ga}_{2} \mathrm{O}_{3}$ and $\mathrm{O}_{2}$, respectively. The binding energies of the $\mathrm{V}_{\mathrm{Ga}}-\mathrm{O}_{\mathrm{N}}$ complex when calculated using either functional are higher than $2 \mathrm{eV}$ at the CBM. We have shown in a previous study ${ }^{57}$ that $\mathrm{O}_{\mathrm{N}}$ will form spontaneously for any value of Fermi energy across the gap and, indeed, in the conduction band, in sharp contrast to $\mathrm{V}_{\mathrm{Ga}}$ (see Fig. 2), which have formation energies of at least $3 \mathrm{eV}$ at the CBM. From the computed point defect formation energies, we therefore expect oxygen to be easily incorporated in the material, with practically no compensation by the formation of $\mathrm{V}_{\mathrm{Ga}}$. We note, however, that vacancies can be introduced, either by non-equilibrium processes or by diffusion from polar surfaces, and that the high binding energy then indicates that all available pairs of vacancies and oxygens will form complexes.

Since $\mathrm{O}$ is close to $\mathrm{N}$ in size and chemistry, $\mathrm{V}_{\mathrm{Ga}}-\mathrm{O}_{\mathrm{N}}$ shares some properties with isolated $\mathrm{V}_{\mathrm{Ga}}$. Figure 2 shows similar transition levels between $\mathrm{V}_{\mathrm{Ga}}$ and $\mathrm{V}_{\mathrm{Ga}} \mathrm{O}_{\mathrm{N}}$, a trend also observed by Lyons et al. ${ }^{16}$ We have shown ${ }^{58}$ that the $-2,-1$, 0 , and +1 states of $\mathrm{V}_{\mathrm{Ga}}$ can bind one, two, three, and four holes on nearest $\mathrm{N}$; here, we find that $\mathrm{V}_{\mathrm{Ga}}-\mathrm{O}_{\mathrm{N}}$, too, can bind 

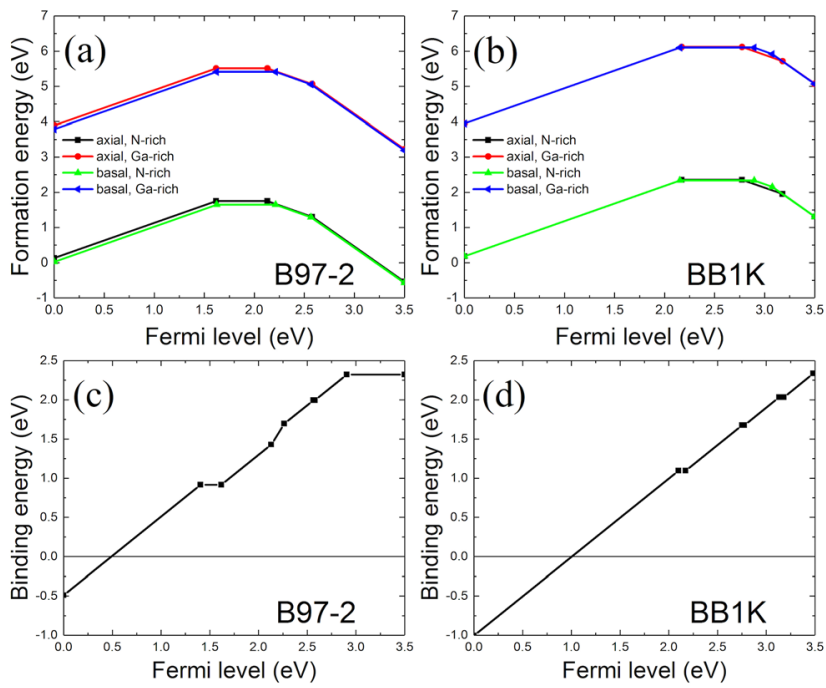

FIG. 1. Formation energies (top panels) and binding energies (bottom panels) of $\mathrm{V}_{\mathrm{Ga}}-\mathrm{O}_{\mathrm{N}}$ calculated using the $\mathrm{B} 97-2$ (left panels) and $\mathrm{BB} 1 \mathrm{~K}$ (right panels) XC functionals. Binding energies are calculated using the formation energies of axial $\mathrm{O}_{\mathrm{N}}$, under $\mathrm{N}$-rich conditions; the positive values represent favorable binding.
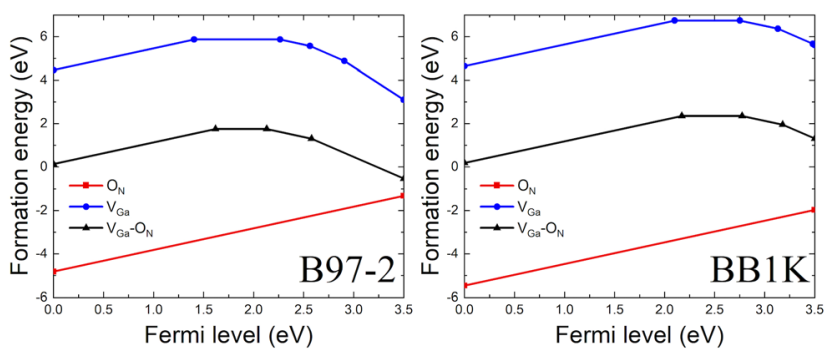

FIG. 2. Formation energies of isolated $\mathrm{V}_{\mathrm{Ga}}, \mathrm{O}_{\mathrm{N}}$, and axial $\mathrm{V}_{\mathrm{Ga}}-\mathrm{O}_{\mathrm{N}}$ defects calculated using the B97-2 (left panel) and BB1K (right panel) $\mathrm{XC}$ functionals.

one, two, and three holes on nearest $\mathrm{N}$ at $-1,0$, and +1 states, respectively. The $(-2 /-)$ transition level of axial (basal) geometry is at $\mathrm{VBM}+2.58(2.57) \mathrm{eV}$ by B97-2 and $\mathrm{VBM}+3.17$ (3.16) eV using the BB1K functional.

Before discussing the optical properties of $\mathrm{V}_{\mathrm{Ga}}-\mathrm{O}_{\mathrm{N}}$, we point out that a defect can have several competing electronic states, which include a compact state and a diffuse state. ${ }^{58}$ The ground-state will be the lower energy state, but under non-equilibrium conditions, such as those following optical ionization, transitions between the states may occur. Often, we only refer to the compact nature of a defect state and consider ionization to or from bands, as shown in Fig. 3. However, in dielectrics, point defects can trap one or more charge carriers in shallow, diffuse hydrogenic orbitals (such as the diffuse hole state shown in Fig. 3), especially when the potential for forming such a diffuse state is an attractive Coulombic well. Such a carrier in a diffuse s-like state has an energy level shifted into the gap relative to the appropriate band edge (depending on the defect charge state), and the ground state of the defect can be either its diffuse state, for example, $\left(V_{G a}-O_{N}\right)^{-2}+h^{+}$(diffuse), or its counterpart compact state, $\left(V_{G a}-O_{N}\right)^{-1}$. These two states can co-exist, and transitions can happen between them, which may be observable depending on both the property of the defect and the kinetics of the experiment.

For the $\mathrm{V}_{\mathrm{Ga}}-\mathrm{O}_{\mathrm{N}}$ complex, we calculate radiative transitions of holes to negatively charged states (see Figs. 3 and 4). We thus consider the optical transition of holes from either the valence band or a diffuse s-like hole level above the valence band to the negative states of this complex. We have shown using effective mass theory, that the diffuse hole of the singly charged defect has an energy $0.20 \mathrm{eV}$ lower than the energy of a hole at the band edge, i.e., the level will lie within the bandgap of $0.20 \mathrm{eV}$ above the VBM, while the diffuse hole of the doubly charged defect has an energy $0.40 \mathrm{eV}$ lower than the energy of a hole at the band edge in GaN. ${ }^{57,58}$

For $\mathrm{V}_{\mathrm{Ga}}-\mathrm{O}_{\mathrm{N}}{ }^{2-}$, the radiative hole capture from the VBM has a green emission peak at $2.33 \mathrm{eV}$ for axial $\mathrm{O}$ and $2.36 \mathrm{eV}$ for basal $\mathrm{O}$. If the hole is captured from the diffuse state of $\mathrm{V}_{\mathrm{Ga}}-\mathrm{O}_{\mathrm{N}}{ }^{2-}$, which is $0.40 \mathrm{eV}$ above the $\mathrm{VBM}$, the transition peak is at $1.93 \mathrm{eV}$ (axial O; $1.96 \mathrm{eV}$ for basal O), which is RL. When both the initial -2 state and the final -1 state of the hole transition are in their diffuse states, so that the associated diffuse hole remains a "spectator" during the process, the corresponding transition peak is at $2.13 \mathrm{eV}$ (axial $\mathrm{O} ; 2.16 \mathrm{eV}$ for basal O), corresponding to YL. For $\mathrm{V}_{\mathrm{Ga}^{-}} \mathrm{O}_{\mathrm{N}}{ }^{1-}$, the radiative

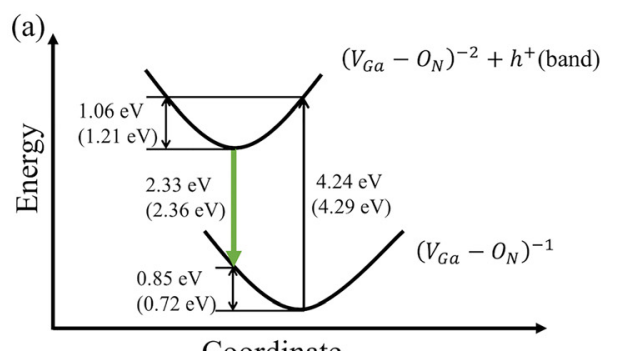

Coordinate

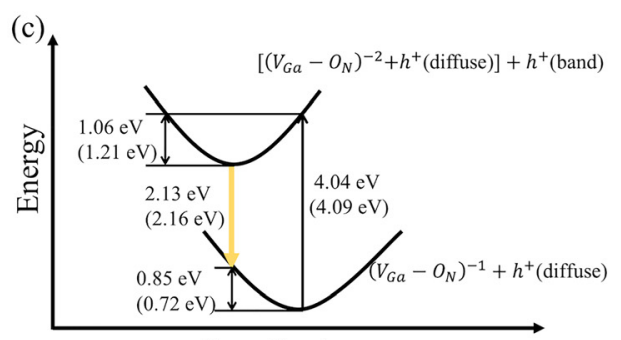

Coordinate

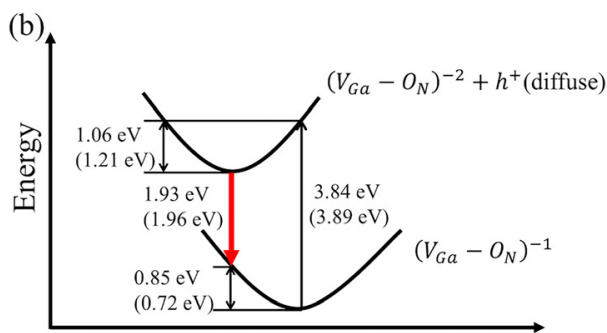

Coordinate

(d)

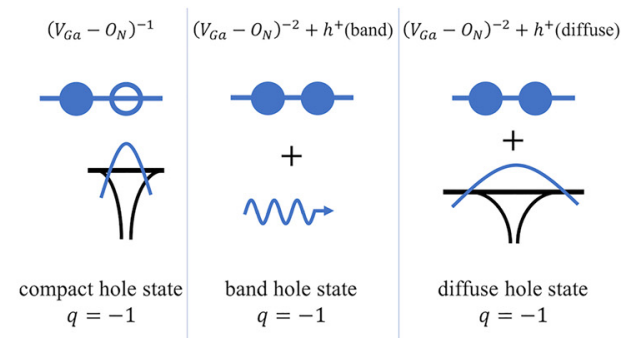

FIG. 3. Configuration-coordinate diagram describing the transition of a hole from the (a) valence band $\left[h^{+}\right.$(band)] or (b) a corresponding diffuse hole [ $h^{+}$(diffuse)] to the -2 state. The transition between two diffuse states is shown in (c). Note that the diffuse hole attracted by different charge states $(q)$ has different energy levels, and hence, we have $h^{+}$(diffuse, $2-$ ) and $h^{+}$(diffuse, $1-)$. The values out of braces correspond to complexes involving axial $\mathrm{O}$ and those in braces to complexes involving basal $\mathrm{O}$, all given by the BB1K functional. A comparison between a compact hole state (trapped in the local defect potential), a band hole state (free in the valence band), and a diffuse hole state (hydrogenic orbit bound by the charged defect) is shown schematically in (d). 

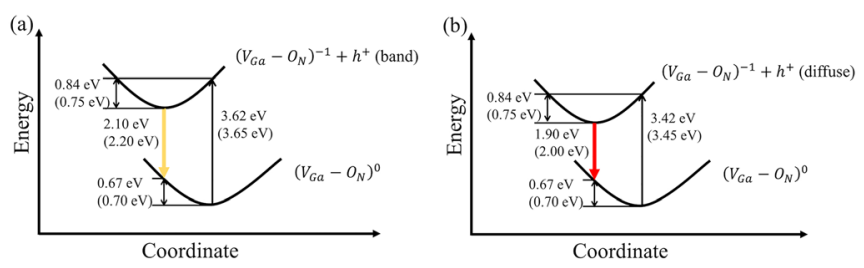

FIG. 4. Configuration-coordinate diagram for the transition of a hole from the valence band or a corresponding diffuse level to the -1 state. The values out of braces are from axial $\mathrm{O}$, and those in braces are from basal $\mathrm{O}$, all given by the $\mathrm{BB} 1 \mathrm{~K}$ functional.

hole capture from the VBM has a yellow emission peak at $2.10 \mathrm{eV}$ for axial $\mathrm{O}$ and $2.20 \mathrm{eV}$ for basal $\mathrm{O}$. If the hole is captured from the diffuse state of $\mathrm{V}_{\mathrm{Ga}^{-}} \mathrm{O}_{\mathrm{N}}{ }^{1-}$, which is $0.20 \mathrm{eV}$ above the VBM, the transition peak is at $1.90 \mathrm{eV}$ (axial O; $2.00 \mathrm{eV}$ for basal $\mathrm{O}$ ). Although -2 is the most stable charge state under equilibrium conditions in $\mathrm{n}-\mathrm{GaN}$, it is useful when comparing to experiment to include other allowed charge states, such as -1 and 0 , which can have long lifetimes in semiconductors. Indeed, several experiments observed multiple bands under different conditions. ${ }^{10,22,24}$

The energy difference between GL and YL peaks from experiments in PL spectra is $0.26 \mathrm{eV}^{8} 0.2 \mathrm{eV},{ }^{59}$ or $0.29 \mathrm{eV},{ }^{22}$ which is comparable to our results. Sedhain identified two peaks at 2.13 and $2.30 \mathrm{eV}$ and attributed them to two geometries of the $\mathrm{V}_{\mathrm{Ga}}-\mathrm{O}_{\mathrm{N}}$ complex: the axial configuration and basal configuration. ${ }^{60}$ In our calculations, we find similar peaks, but we do not find such a big difference between axial and basal configurations; however, the $0.20 \mathrm{eV}$ change between compact and diffuse states is comparable. Reshchikov et al. observed a transformation of the YL into the GL band and attributed the bands to two charge states of the same dominant acceptor, ${ }^{8}$ which is consistent with our results where compact hole capture by -2 and -1 states of $\mathrm{V}_{\mathrm{Ga}}-\mathrm{O}_{\mathrm{N}}$ gives rise to $\mathrm{GL}$ and $\mathrm{YL}$, respectively. Later, they also observed that the lifetime of the GL band stays unchanged up to $70 \mathrm{~K}$ and then increases by a factor of 20 at $300 \mathrm{~K}$ and attributed the change to the existence of an excited state. ${ }^{9}$ We propose that this lifetime increase in GL may be a result of trapped hydrogenic diffuse holes being released to the valence band as the temperature increases, which increases the probability of occurrence of the first process in Fig. 3. Concurrently, the lifetime of YL is decreased by a reduction in the rate of the last process in Fig. 3, while the occurrence of the first process in Fig. 4 is also reduced due to the increase in the Fermi level with temperature, as observed in their experiment. ${ }^{9}$ In unintentionally doped GaN layers grown by MBE, Reshchikov et al. observed a RL band with a maximum at about $1.88 \mathrm{eV}$ and a GL band with a maximum at about $2.37 \mathrm{eV} .^{20}$ Our calculated RL and GL peaks are very close (see Figs. 3 and 4). They speculate that the defects are partially nonradiative (with strong electronphonon coupling) and related to Ga atoms. Although the large lattice distortion by hole capture has been reported previously $^{61}$ and is seen here, we do not find gallium vacancy complexes as a cause of nonradiative recombination in $\mathrm{GaN}$, as concluded from a previous calculation. ${ }^{19}$

Reshchikov et al. have resolved a YL band which has a maximum at $2.20 \mathrm{eV}$ and a zero phonon line (ZPL) at $2.57 \mathrm{eV}^{7,21,24,62}$ or another YL band which has a maximum at
$2.10 \mathrm{eV}$ and $\mathrm{ZPL}$ at $2.36 \mathrm{eV} .^{24,63}$ The difference between the band maximum and ZPL is the relaxation after the carrier capture process, which in the above YL bands are $0.37 \mathrm{eV}$ and $0.26 \mathrm{eV}$. In our calculations, the relaxation energy ranges from $0.67 \mathrm{eV}$ to $0.85 \mathrm{eV}$. The small relaxation resolved from the above experiments is quite unlikely according to both previous calculations ${ }^{16,61}$ and our findings. In the defect processes we study, that the $\mathrm{N}$ surrounding the Ga vacancy relaxes strongly upon binding or releasing a hole when YL takes place. We suggest that a reinvestigation of the tails in the experimental PL spectra is called for to help resolve alternative sources of YL, whereas the small relaxation energies from the work of Reshchikov et al. should be associated with nontrivial defect states, where a primary relaxation process would be dampened, for example, by the interaction with another (e.g., charge-balancing) defect or in extended regions with different dielectric and elastic response properties that would form macroscopic defects or possibly dislocations.

In the literature, there are many discussions on electron traps that give rise to $\mathrm{YL}$, by $\mathrm{C}_{\mathrm{N}},{ }^{14} \mathrm{C}_{\mathrm{N}}-\mathrm{O}_{\mathrm{N}},{ }^{15}$ or $\mathrm{V}_{\mathrm{Ga}}$ complexes. ${ }^{16}$ However, the transitions claimed to cause YL emission are all close to the valence band. For example, Lyons et al. identified electron capture by the +1 state of $\mathrm{V}_{\mathrm{Ga}}-3 \mathrm{H}$ and $\mathrm{V}_{\mathrm{Ga}}-\mathrm{O}_{\mathrm{N}}-2 \mathrm{H}$ complexes to be the origin of $\mathrm{YL}$, while their transition levels of $(+/ 0)$ are less than $1 \mathrm{eV}$ above the VBM where it is not n-type. Indeed, if electron capture is to give rise to an emission peak in the visible region, the defect level must be in the lower half of the bandgap. Instead, our calculations indicate that YL bands may arise from hole capture following the photoexcitation of electrons to transition levels in the upper region of the bandgap. One of the crucial parts of the reasoning for the transition from the conduction band or shallow donors to a deep acceptor has been the observation, on heating the sample from very low $\mathrm{T}$, of a shift in the PL signal by the energy approximately equal to the ionization potential of a shallow donor. ${ }^{12}$ However, this energy shift is also comparable with the ionization energy of a hole trapped on a neutral (rather than negative) acceptor (20-50 meV according to our calculations). The shorter lifetime of the $\mathrm{GL}^{59}$ is consistent with transitions involving ionization of shallow acceptors, whereas YL and RL could be seen to involve initial trapping of holes on the deep diffuse states, where they will stay longer. Of course, processes involving electron capture from the conduction band may still be crucial; our calculations, however, demonstrate that the presence of holes, which is still not well understood in $\mathrm{GaN}$, may also offer key recombination pathways necessary to understand experimental results.

In conclusion, $\mathrm{V}_{\mathrm{Ga}}-\mathrm{O}_{\mathrm{N}}$ has a lower formation energy compared to isolated $\mathrm{V}_{\mathrm{Ga}}$, while the transition levels of both defects in the bandgap are quite similar. While $\mathrm{V}_{\mathrm{Ga}}-\mathrm{O}_{\mathrm{N}}$ and $\mathrm{V}_{\mathrm{Ga}}$ have similar hole capture peaks, $\mathrm{V}_{\mathrm{Ga}}-\mathrm{O}_{\mathrm{N}}$ can contribute to luminescence observed in PL spectra due to its lower formation energy and thus higher concentration. The YL and accompanied RL and GL can be explained as originating from transitions involving different charge states of $\mathrm{V}_{\mathrm{Ga}}-\mathrm{O}_{\mathrm{N}}$, taking into account processes involving bound diffuse holes and delocalized band holes. The model suggests why YL, GL and RL bands are often observed in combination and why multiple peaks are found for red and yellow luminescence. 
Z.X. thanks the China Scholarship Council (CSC) for support, as well as the Leverhulme Trust. We are grateful to Alex Ganose and Stephen Shevlin for technical help and Audrius Alkauskas and Su-Huai Wei for useful discussions. The EPSRC is acknowledged for funding (Nos. EP/ $\mathrm{K} 038419$, EP/I03014X, and EP/K016288). A.W. was supported by the Royal Society. Computational resources were provided through the Materials Chemistry Consortium on EPSRC Grant No. EP/L000202. We also acknowledge PRACE for awarding us access to the ARCHER supercomputer, UK.

${ }^{1} \mathrm{H}$. Morkoç, Handbook of Nitride Semiconductors and Devices (WileyVCH, Weinheim, 2008).

${ }^{2}$ T. Y. Seong, J. Han, H. Amano, and H. Morkoc, III-Nitride Based Light Emitting Diodes and Applications (Springer, Berlin, 2013).

${ }^{3}$ V. Garbe, B. Abendroth, H. Stöcker, A. Gavrilov, D. Cohen-Elias, S. Mehari, D. Ritter, and D. C. Meyer, Cryst. Res. Technol. 50, 425 (2015).

${ }^{4}$ T. Suski, P. Perlin, H. Teisseyre, M. Leszczynski, I. Grzegory, J. Jun, M. Bockowski, S. Porowski, and T. D. Moustakas, Appl. Phys. Lett. 67, 2188 (1995).

${ }^{5}$ K. Saarinen, T. Laine, S. Kuisma, J. Nissilä, P. Hautojärvi, L. Dobrzynski, J. Baranowski, K. Pakula, R. Stepniewski, M. Wojdak, a Wysmolek, T. Suski, M. Leszczynski, I. Grzegory, and S. Porowski, Phys. Rev. Lett. 79, 3030 (1997).

${ }^{6}$ F. J. Xu, B. Shen, L. Lu, Z. L. Miao, J. Song, Z. J. Yang, G. Y. Zhang, X. P. Hao, B. Y. Wang, X. Q. Shen, and H. Okumura, J. Appl. Phys. 107, 023528 (2010).

${ }^{7}$ M. A. Reshchikov, J. D. McNamara, F. Zhang, M. Monavarian, A. Usikov, H. Helava, Y. Makarov, and H. Morkoc, Phys. Rev. B 94, 035201 (2016).

${ }^{8}$ M. A. Reshchikov, H. Morkoç, S. S. Park, and K. Y. Lee, Appl. Phys. Lett. 81, 4970 (2002).

${ }^{9}$ M. A. Reshchikov, S. S. Park, K. Y. Lee, and H. Morkoç, Physica B 340-342, 448 (2003).

${ }^{10}$ C. Díaz-Guerra, J. Piqueras, and A. Cavallini, Appl. Phys. Lett. 82, 2050 (2003).

${ }^{11}$ M. A. Reshchikov, D. O. Demchenko, A. Usikov, H. Helava, and Y. Makarov, Phys. Rev. B 90, 235203 (2014).

${ }^{12}$ T. Ogino and M. Aoki, Jpn. J. Appl. Phys. 19, 2395 (1980).

${ }^{13}$ J. Neugebauer and C. G. Van de Walle, Appl. Phys. Lett. 69, 503 (1996).

${ }^{14}$ J. L. Lyons, A. Janotti, and C. G. Van De Walle, Appl. Phys. Lett. 97, 152108 (2010).

${ }^{15}$ D. O. Demchenko, I. C. Diallo, and M. A. Reshchikov, Phys. Rev. Lett. 110, 087404 (2013).

${ }^{16}$ J. L. Lyons, A. Alkauskas, A. Janotti, and C. G. Van de Walle, Phys. Status Solidi B 252, 900 (2015).

${ }^{17}$ J. Yang, D. G. Zhao, D. S. Jiang, P. Chen, Z. S. Liu, L. C. Le, X. J. Li, X. G. He, J. P. Liu, S. M. Zhang, H. Wang, J. J. Zhu, and H. Yang, J. Appl. Phys. 115, 163704 (2014).

${ }^{18}$ C. Bozdog, G. D. Watkins, H. Sunakawa, N. Kuroda, and A. Usui, Phys. Rev. B 65, 125207 (2002).

${ }^{19}$ C. E. Dreyer, A. Alkauskas, J. L. Lyons, J. S. Speck, and C. G. Van De Walle, Appl. Phys. Lett. 108, 141101 (2016).

${ }^{20}$ M. A. Reshchikov, M. H. Zhang, C. Jie, P. Visconti, Y. Feng, and H. Morkoc, Mater. Res. Soc. Symp. Proc. 639, G6.7 (2001).

${ }^{21}$ M. A. Reshchikov, D. O. Demchenko, A. Usikov, H. Helava, and Y. Makarov, Proc. SPIE 9363, 93630L (2015).

${ }^{22}$ S. Ito, T. Nakagita, N. Sawaki, H. S. Ahn, M. Irie, T. Hikosaka, Y. Honda, M. Yamaguchi, and H. Amano, Jpn. J. Appl. Phys. 53, 11RC02 (2014).

${ }^{23}$ M. A. Reshchikov, H. Morkoç, S. S. Park, and K. Y. Lee, Mater. Res. Soc. Symp. Proc. 693, I6.19.1 (2002).

${ }^{24}$ M. A. Reshchikov, J. D. McNamara, M. Toporkov, V. Avrutin, H. Morkoç, A. Usikov, H. Helava, and Y. Makarov, Sci. Rep. 6, 37511 (2016).

${ }^{25}$ M. A. Reshchikov, A. Usikov, H. Helava, and Y. Makarov, Appl. Phys. Lett. 104, 032103 (2014).

${ }^{26}$ J. Neugebauer and C. G. Van De Walle, Phys. Rev. B 50, 8067 (1994).

${ }^{27}$ F. Gao, E. J. Bylaska, and W. J. Weber, Phys. Rev. B 70, 245208 (2004).

${ }^{28}$ K. Laaksonen, M. G. Ganchenkova, and R. M. Nieminen, J. Phys.: Condens. Matter 21, 015803 (2009).

${ }^{29}$ G. Miceli and A. Pasquarello, Microelectron. Eng. 147, 51 (2015).

${ }^{30}$ I. C. Diallo and D. O. Demchenko, Phys. Rev. Appl. 6, 064002 (2016).
${ }^{31}$ A. Kyrtsos, M. Matsubara, and E. Bellotti, Phys. Rev. B 93, 245201 (2016).

${ }^{32} \mathrm{~T}$. Mattila and M. Nieminen, in Proceedings of the III-V Nitride Symposium 189th ECS Meeting, Los Angeles, May 1996.

${ }^{33}$ A. Katre, J. Carrete, T. Wang, G. K. H. Madsen, and N. Mingo, Phys. Rev. Mater. 2, 050602(R) (2018).

${ }^{34}$ S. Hautakangas, I. Makkonen, V. Ranki, M. J. Puska, K. Saarinen, X. Xu, and D. C. Look, Phys. Rev. B 73, 193301 (2006).

${ }^{35}$ N. T. Son, C. G. Hemmingsson, T. Paskova, K. R. Evans, A. Usui, N. Morishita, T. Ohshima, J. Isoya, B. Monemar, and E. Janzén, Phys. Rev. B 80, 153202 (2009).

${ }^{36}$ A. A. Sokol, S. T. Bromley, S. A. French, C. R. A. Catlow, and P. Sherwood, Int. J. Quantum Chem. 99, 695 (2004).

${ }^{37}$ P. Sherwood, A. H. de Vries, M. F. Guest, G. Schrecken-bach, C. R. A. Catlow, S. A. French, A. A. Sokol, S. T. Bromley, W. Thiel, A. J. Turner, S. Billeter, F. Terstegen, S. Thiel, J. Kendrick, S. C. Rogers, J. Casci, M. Watson, F. King, E. Karlsen, M. Sjøvoll, A. Fahmi, A. Schäfer, and C. Lennartz, J. Mol. Struct. 632, 1 (2003).

${ }^{38}$ C. R. A. Catlow, J. Buckeridge, M. R. Farrow, A. J. Logsdail, and A. A. Sokol, Quantum Mechanical/Molecular Mechanical (QM/MM) Approaches: Flawed Perfection (Wiley-VCH Verlag GmbH, Weinheim, 2017).

${ }^{39}$ P. J. Wilson, T. J. Bradley, and D. J. Tozer, J. Chem. Phys. 115, 9233 (2001).

${ }^{40}$ C. Adamo and V. Barone, J. Chem. Phys. 110, 6158 (1999).

${ }^{41}$ J. Heyd, G. E. Scuseria, and M. Ernzerhof, J. Chem. Phys. 124, 219906 (2006).

${ }^{42}$ W. Stevens, M. Krauss, H. Basch, and P. Jasien, Can. J. Chem. 70, 612 (1992).

${ }^{43}$ M. Miskufova, Ph.D. thesis, University College London, 2011.

${ }^{44}$ J. Buckeridge, C. R. A. Catlow, D. O. Scanlon, T. W. Keal, P. Sherwood, M. Miskufova, A. Walsh, S. M. Woodley, and A. A. Sokol, Phys. Rev. Lett. 114, 016405 (2015).

${ }^{45}$ F. Weigend and R. Ahlrich, Phys. Chem. Chem. Phys. 7, 3297 (2005).

${ }^{46}$ Y. Zhao, B. J. Lynch, and D. G. Truhlar, J. Phys. Chem. A 108, 2715 (2004).

${ }^{47}$ J. Buckeridge, C. R. A. Catlow, D. O. Scanlon, T. W. Keal, P. Sherwood, M. Miskufova, A. Walsh, S. M. Woodley, and A. A. Sokol, Phys. Rev. Lett. 115, 029702 (2015).

${ }^{48}$ C. R. A. Catlow, Z. X. Guo, M. Miskufova, S. A. Shevlin, A. G. H. Smith, A. A. Sokol, D. J. Wilson, and S. M. Woodley, Philos. Trans. R. Soc., A 368, 3379 (2010).

${ }^{49}$ S. Metz, J. Kästner, A. A. Sokol, T. W. Keal, and P. Sherwood, WIREs Comput. Mol. Sci. 4, 101 (2014).

${ }^{50}$ M. F. Guest, I. J. Bush, H. J. Van Dam, P. Sherwood, J. M. H. Thomas, J. H. Van Lenthe, R. W. Havenith, and J. Kendrick, Mol. Phys. 103, 719 (2005).

${ }^{51}$ J. D. Gale, J. Chem. Soc., Faraday Trans. 93, 629 (1997).

${ }^{52}$ A. Walsh, J. Buckeridge, C. R. A. Catlow, A. J. Jackson, T. W. Keal, M. Miskufova, P. Sherwood, S. A. Shevlin, M. B. Watkins, S. M. Woodley, and A. A. Sokol, Chem. Mater. 25, 2924 (2013).

${ }^{53}$ D. J. Wilson, A. A. Sokol, S. A. French, and C. R. A. Catlow, The Rôle of Defects in Photographic Latent Image Formation (Mater. Res. Soc. Symp. Proc., 2005), p. 848.

${ }^{54}$ A. A. Sokol, S. A. French, S. T. Bromley, C. R. A. Calow, H. J. J. van Dam, and P. Sherwood, Faraday Discuss. 134, 267 (2007).

${ }^{55}$ D. O. Scanlon, C. W. Dunnill, J. Buckeridge, S. A. Shevlin, A. J. Logsdail, S. M. Woodley, C. R. A. Catlow, M. J. Powell, R. G. Palgrave, I. P. Parkin, G. W. Watson, T. W. Keal, P. Sherwood, A. Walsh, and A. A. Sokol, Nat. Mater. 12, 798 (2013).

${ }^{56}$ Q. Yan, A. Janotti, M. Scheffler, and C. G. Van De Walle, Appl. Phys. Lett. 100, 142110 (2012).

${ }^{57}$ Z. Xie, Y. Sui, J. Buckeridge, C. R. A. Catlow, T. W. Keal, P. Sherwood, A. Walsh, D. O. Scanlon, S. M. Woodley, and A. A. Sokol, Phys. Status Solidi A 214, 1600445 (2017)

${ }^{58}$ Z. Xie, Y. Sui, J. Buckeridge, C. R. A. Catlow, T. W. Keal, P. Sherwood, M. R. Farrow, D. O. Scanlon, S. M. Woodley, and A. A. Sokol, e-print arXiv:cond-mat/1803.06273 (2018).

${ }^{59}$ M. A. Reshchikov, A. Usikov, H. Helava, and Y. Makarov, J. Electron. Mater. 44, 1281 (2015).

${ }^{60}$ A. Sedhain, J. Li, J. Y. Lin, and H. X. Jiang, Appl. Phys. Lett. 96, 151902 (2010).

${ }^{61}$ J. L. Lyons and C. G. Van de Walle, npj Comput. Mater. 12, 1 (2017).

${ }^{62}$ M. A. Reshchikov, A. Usikov, H. Helava, Y. Makarov, V. Prozheeva, I. Makkonen, F. Tuomisto, J. H. Leach, and K. Udwary, Sci. Rep. 7, 9297 (2017).

${ }^{63}$ M. A. Reshchikov, J. D. Mcnamara, H. Helava, and A. Usikov, Sci. Rep. 8, 8091 (2018). 